\title{
FERTILITY AND SELECTION IN GARDEN HYACINTH
}

\section{ZYGOTIC SELECTION}

S. VED BRAT

Botany School, Oxford University

Received 13.iv.68

\section{Introduction}

Chromosome numbers of garden hyacinths vary from diploid to tetraploid. All varieties produce seed, but their actual fertility is not known. In diploid-trisomic crosses, the trisomic as female gives better fertility and greater transmission of the extra chromosome (Ved Brat, 1967a). The present paper deals with diploid, triploid, tetraploid and some aneuploids (table 1).

TABLE 1

Chromosome complements of varieties. In the text, initial letters are used as abbreviations

\begin{tabular}{|c|c|c|c|c|c|}
\hline \multirow[b]{2}{*}{ Variety } & \multirow[b]{2}{*}{$2 n$} & \multicolumn{4}{|c|}{$\begin{array}{l}\text { Chromosome } \\
\text { complement }\end{array}$} \\
\hline & & $L$ & $L^{n}$ & $M$ & $S$ \\
\hline $\begin{array}{l}2 x \\
\text { Borah } \\
\text { Early French Roman } \\
\text { Gypsy Queen } \\
\text { La Victoire } \\
\text { Prince Henry } \\
\text { Princess Irene } \\
\text { Pink Pearl } \\
\text { Salmoneta }\end{array}$ & 16 & 6 & 2 & 4 & 4 \\
\hline $\begin{array}{l}3 x-1 \\
\text { Delight }\end{array}$ & 23 & 9 & 3 & 6 & 5 \\
\hline $\begin{array}{l}3 x \\
\text { Anne Marie } \\
\text { Lord Balfour } \\
\text { Lady Derby } \\
\text { Grand Maitre } \\
\text { King of Blues } \\
\text { Queen of Pinks }\end{array}$ & 24 & 9 & 3 & 6 & 6 \\
\hline $\begin{array}{l}3 x+3 \\
\text { L'Innocence }\end{array}$ & 27 & 12 & 3 & 6 & 6 \\
\hline $\begin{array}{l}3 x+4 \\
\quad \text { Vistula }\end{array}$ & 28 & 13 & 3 & 6 & 6 \\
\hline $\begin{array}{l}4 x-3 \\
\quad \text { Carnegie }\end{array}$ & 29 & 13 & 3 & 7 & 6 \\
\hline $\begin{array}{l}4 x-2 \\
\text { Delft Blue }\end{array}$ & 30 & 12 & 3 & 8 & 7 \\
\hline${ }^{4 x}$ Blue Giant & 32 & 12 & 4 & 8 & 8 \\
\hline
\end{tabular}

* Present address: Botany Department, Panjab University, Chandigarh-14, India. 
Darlington et al. (1951) describe Lord Balfour as a diploid variety with dark blue flowers, but the present bulbs provided by Messrs Sutton were triploid and produced bluish pink flowers. The experimental techniques have been described (see Ved Brat, 1967a).

\section{Crossability}

Most of the varieties are self-incompatible. Blue Giant, the only tetraploid, is self-compatible and sets seed both after bagging and open pollinations. Intervarietal crosses are mostly successful, irrespective of the chromosome numbers of the varieties. But, some crosses between the diploids fail completely (table 2).

TABLE 2

Crossability and seed set of diploid hyacinths

\begin{tabular}{lcccc}
$\quad$ & \multicolumn{3}{c}{} & \multicolumn{3}{c}{ Seeds } \\
$\quad$ Cross* & Fruits & $\overbrace{\text { Plump }}$ & Shrivelled & Per fruit \\
L.V. $\times$ S. & 4 & 28 & nil & 7.0 \\
P.I. $\times$ B. & 12 & 82 & 14 & 8.0 \\
S. $\times$ P.P. & 6 & 24 & 7 & $5 \cdot 16$ \\
G.Q. $\times$ P.H. & 1 & 1 & nil & 1.0
\end{tabular}

* S. $\times$ L.V., P.P. $\times$ P.I., P.I. $\times$ P.P., and P.I. $\times$ L.V. crosses are all unsuccessful. G.Q. $\times$ P.H. produced only one seed when whole inflorescence was pollinated. L.V. $\times$ S. produced 91 per cent. viable seeds.

Amongst the aneuploids, well-developed seedless fruits are sometimes produced, presumably owing to the stimulus of pollination but failure of fertilisation, e.g. in a cross between hyacinth Delight $(3 x-1)$ and Anne Marie $(3 x)$.

\section{SeEd SET AND VIABILITy}

\section{(a) Diploid-triploid}

Fertility varies from one cross to another (table 3 ). When two varieties such as Pink Pearl and Lord Balfour are crossed reciprocally, the triploid seed parent gives approximately eleven times more seed than the diploid. This is a reflection of the greater proportion of viable seeds produced rather than the number of ovules per ovary. These results are similar to those in earlier known cases (see Upcott and Philp, 1939; tables X and XI). But in the other genera the aneuploids do not survive at all, whereas they are as vigorous as the euploids in Hyacinthus.

\section{(b) Diploid-tetraploid}

Reciprocal crosses between diploids and tetraploids give similar results (table 4) which again resemble the general pattern in diploid-tetraploid crosses (see Woodell and Valentine, 1961; table 5), especially those of maize (Randolf, 1935), Datura (Sansome et al., 1942) and Secale cereale (Hakansson et al., 1950) where the viable seeds are produced at low frequency in either direction. The hyacinth tetraploids produce mostly inviable seeds which show a wide range of size variation suggesting that the elimination occurs throughout seed development. 


\section{(c) Tetraploid-triploid}

Blue Giant crossed with the triploid Lord Balfour and G. Maitre (table 4) gave better fertility than the diploid-triploid and diploid-tetraploid crosses.

TABLE 3

Fertility in diploid-triploid crosses

\begin{tabular}{|c|c|c|c|c|c|c|}
\hline \multirow[b]{2}{*}{ Cross } & \multirow[b]{2}{*}{ Fruits } & \multicolumn{3}{|c|}{ Seeds ripened and sown } & \multirow{2}{*}{$\begin{array}{c}\text { Ovules } \\
\text { per } \\
\text { fruit }\end{array}$} & \multirow{2}{*}{$\begin{array}{l}\text { Percentage } \\
\text { of ovules } \\
\text { giving } \\
\text { viable seeds }\end{array}$} \\
\hline & & Plump & Shrivelled & Viable & & \\
\hline \multicolumn{7}{|l|}{$2 x \times 3 x$} \\
\hline P.P. $\times$ L.B. & 64 & 154 & 160 & 66 & 26 & $3 \cdot 7$ \\
\hline L.V. × A.M. & 4 & 16 & 12 & 2 & 24 & $2 \cdot 1$ \\
\hline L.V. $\times$ L.D. & 16 & 119 & 42 & 0 & 24 & - \\
\hline P.H. $\times$ L.D. & 4 & 7 & 4 & 2 & 18 & $2 \cdot 5$ \\
\hline P.H. $\times$ A.M. & 4 & 8 & 10 & 15 & 18 & 20.8 \\
\hline \multicolumn{7}{|l|}{$3 x \times 2 x$} \\
\hline L.B. $\times$ P.P. & 18 & 199 & 41 & 168 & 24 & $40 \cdot 0$ \\
\hline L.D. $\times$ P.P. & 30 & 126 & 48 & 57 & 20 & 9.5 \\
\hline Q.B. ×P.P. & 22 & 72 & 120 & 25 & 18 & $6 \cdot 3$ \\
\hline A.M. $\times$ F.R. & 17 & 85 & 14 & 57 & 24 & 17.9 \\
\hline A.M. $\times$ P.I. & 15 & 81 & 6 & 60 & 24 & $16 \cdot 7$ \\
\hline
\end{tabular}

Evidently, the unbalanced pollen grains of the triploid are more effective on the tetraploid than on the diploid. Also, the fertility of a cross cannot depend entirely on the balance of pollen grains, as both pollen grains and eggs are balanced in the latter cross.

TABLE 4

Fertility of tetraploid when crossed with diploid and triploid

\begin{tabular}{|c|c|c|c|c|c|c|}
\hline \multirow[b]{2}{*}{ Cross } & \multirow[b]{2}{*}{ Fruit } & \multicolumn{3}{|c|}{ Seeds ripened and sown } & \multirow{2}{*}{$\begin{array}{l}\text { Total } \\
\text { seeds } \\
\text { per fruit }\end{array}$} & \multirow{2}{*}{$\begin{array}{l}\text { Viable } \\
\text { seeds } \\
\text { per fruit }\end{array}$} \\
\hline & & Plump & Shrivelled & Viable & & \\
\hline \multicolumn{7}{|l|}{$2 x \times 4 x$} \\
\hline P.P. $\times$ B.G. & 4 & 4 & 11 & 4 & $4 \cdot 25$ & $1 \cdot 00$ \\
\hline \multicolumn{7}{|l|}{$4 x \times 2 x$} \\
\hline B.G. $\times$ P.P. & 23 & 17 & 155 & 5 & $7 \cdot 98$ & $0 \cdot 22$ \\
\hline \multicolumn{7}{|l|}{$4 x \times 3 x$} \\
\hline $\begin{array}{l}\text { B.G. } \times \text { G.M. } \\
\text { B.G. } \times \text { L.B. }\end{array}$ & $\begin{array}{l}17 \\
40\end{array}$ & $\begin{array}{l}127 \\
374\end{array}$ & $\begin{array}{l}146 \\
232\end{array}$ & $\begin{array}{l}112 \\
200\end{array}$ & $\begin{array}{l}16 \cdot 06 \\
15 \cdot 15\end{array}$ & $\begin{array}{l}6 \cdot 59 \\
5 \cdot 00\end{array}$ \\
\hline
\end{tabular}

\section{(d) Aneuploids}

Aneuploids were crossed with the diploids in one direction only (table 5). When Vistula was crossed with Pink Pearl, two types of seeds, large plump and small papery, were produced. The absence of the intermediate size suggests that seed abortion occurs only during early seed development. The fertility results of the near tetraploid (Delft Blue) are more similar to the tetraploids than the diploids. 


\section{Chromosomal constitution of progenies}

Chromosome counts were made of both embryos and seedlings from diploid-triploid crosses but only from seedlings in the other cases.

TABLE 5

Fertility of aneuploids when crossed with diploids and triploids

\begin{tabular}{|c|c|c|c|c|c|c|}
\hline \multirow[b]{2}{*}{ Cross } & \multirow[b]{2}{*}{ Fruits } & \multicolumn{3}{|c|}{ Seeds ripened and sown } & \multirow{2}{*}{$\begin{array}{l}\text { Total } \\
\text { seeds } \\
\text { per fruit }\end{array}$} & \multirow{2}{*}{$\begin{array}{l}\text { Viable } \\
\text { seeds } \\
\text { per fruit }\end{array}$} \\
\hline & & Plump & Shrivelled & Viable & & \\
\hline $\begin{array}{c}(3 x-1) \times 2 x \\
\text { D. } \times \text { P.I. }\end{array}$ & 65 & 501 & 124 & 408 & $9 \cdot 62$ & $6 \cdot 27$ \\
\hline $\begin{array}{r}(3 x+3) \times 2 x \\
\text { L.I. } \times \text { P.P. }\end{array}$ & 48 & 297 & 69 & 177 & $7 \cdot 62$ & $3 \cdot 69$ \\
\hline $\begin{array}{c}(3 x+4) \times 2 x \\
\text { V. } \times \text { P.P. }\end{array}$ & 8 & 54 & 4 & 46 & $7 \cdot 25$ & $5 \cdot 75$ \\
\hline $\begin{aligned}(4 x-2) & \times 2 x \\
\text { D.B. } & \times \text { P.P. }\end{aligned}$ & 11 & 24 & 14 & 19 & $3 \cdot 45$ & 1.73 \\
\hline $\begin{array}{c}(4 x-3) \times 3 x \\
\text { C. } \times \text { Q.P. } \\
\text { G. } \times \text { G.M. }\end{array}$ & $\begin{array}{l}35 \\
15\end{array}$ & $\begin{array}{r}131 \\
70\end{array}$ & $\begin{array}{r}121 \\
50\end{array}$ & $\begin{array}{r}156 \\
?\end{array}$ & $\begin{array}{l}7.20 \\
8.00\end{array}$ & $\begin{array}{r}4.45 \\
?\end{array}$ \\
\hline $\begin{array}{c}3 x \times(4 x-3) \\
\text { L.B. } \times \text { C. }\end{array}$ & 11 & 56 & 10 & ? & $6 \cdot 00$ & ? \\
\hline
\end{tabular}

(i) Embryos

(a) Diploid-triploid crosses

Two abnormal genotypes, one with a fragment isochromosome and the other with a long chromosome carrying a deletion, were found (plate I, figs. 1 and 2). The former presumably arose from the misdivision of a small

TABLE 6

Chromosome distribution in the embryonic progenies of diploid-triploid crosses. Data deduced from embryos and endosperms or both from ovules studied two weeks after pollinations

\begin{tabular}{|c|c|c|c|c|c|c|c|c|c|c|c|}
\hline \multirow[b]{2}{*}{ Cross } & \multicolumn{9}{|c|}{ Chromosome number } & \multirow{2}{*}{\multicolumn{2}{|c|}{$\begin{array}{c}\text { Mean } \\
\text { Total } \\
\begin{array}{c}\text { chromosome } \\
\text { number }\end{array}\end{array}$}} \\
\hline & 16 & 17 & 18 & 19 & 20. & 21 & 22 & 23 & 24 & & \\
\hline $2 x \times 3 x$ & 3 & 2 & 11 & 15 & 13 & 21 & 17 & 2 & - & 84 & $20 \cdot 07$ \\
\hline $3 x \times 2 x$ & 3 & 5 & 8 & 16 & 23 & 16 & 10 & 5 & 1 & 87 & 19.95 \\
\hline
\end{tabular}

chromosome. The chromosome with the deleted arm is probably nucleolar, as suggested by the usual numerical balance of chromosomes according to which a complement containing 12 long chromosomes should include 3 nucleolar ones.

Chromosome numbers of the embryos of diploid-triploid reciprocal crosses more or less conform to the expected binomial distribution (table 6). This suggests that the pollen grains and the eggs of a triploid are equally effective irrespective of their chromosome numbers. But this is unlike those 
of the trisomic, where the balanced gametes are at an advantage over the unbalanced ones (Ved Brat, 1967a). The present data are similar in the reciprocal crosses, both for total chromosome numbers and for the $L$, $M$ and $S$ chromosomes respectively (text-fig. I). Darlington and Mather (1944) reported a negative correlation of $L$ chromosomes over $M+S$ in the pollen grains, but it is absent in the embryos (table 7). Thus, the distribution frequencies of $L, M$ and $S$ chromosomes in the embryos differ from those

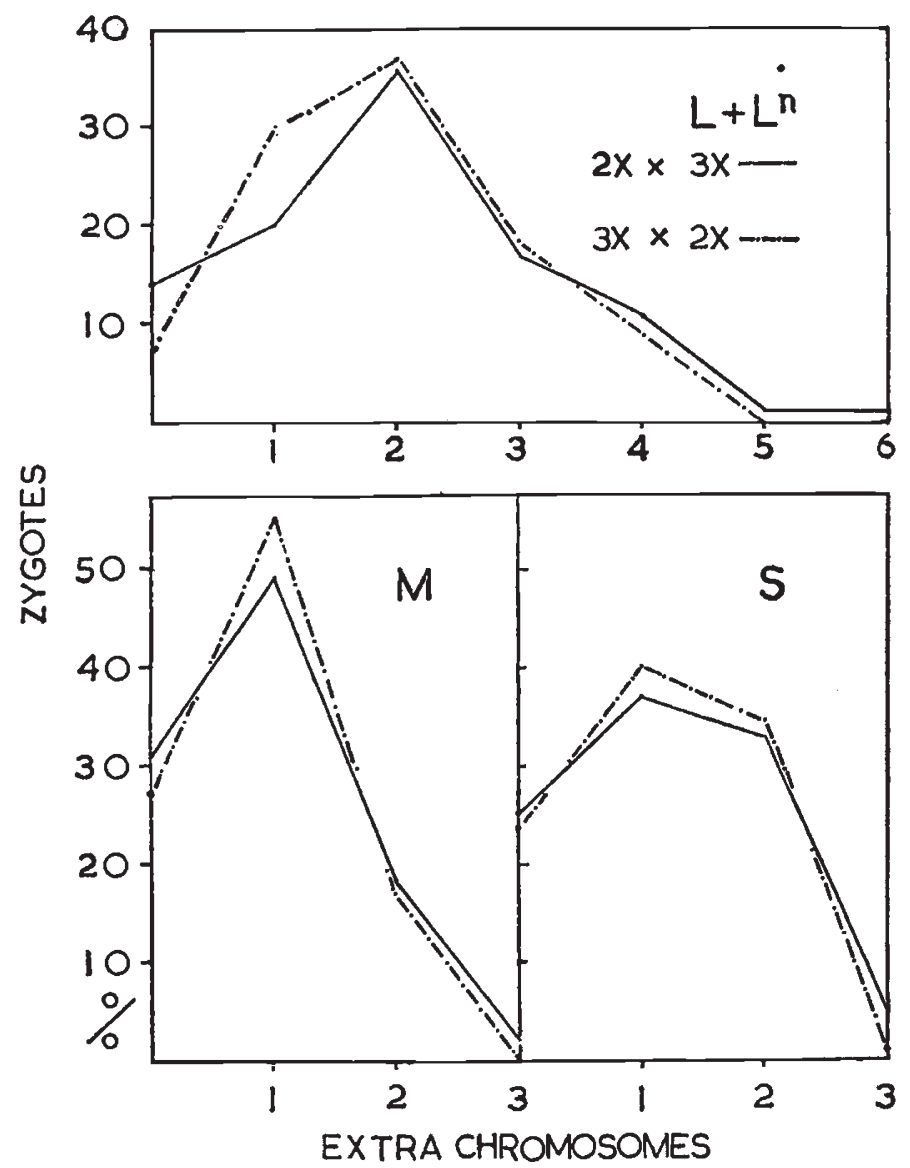

FIG. 1.-Distribution of the extra chromosomes of three types in the embryos of diploidtriploid crosses. Note the formation of genotypes with more than the expected extra chromosomes.

in the pollen grains. The peaks of the distribution curves of $M$ and $S$ chromosomes have shifted from zero to one (text-fig. 1). In the embryos, however, chromosomes of the individual type exceed the limits of expectation from the trivalents. This can arise from the illegitimate segregation of univalents or quadrivalents formed during meiosis (Brock, 1955). Subhaploid pollen reported earlier in the triploid hyacinth Anne Marie (Ved Brat, 1967b) is also suggestive of the same fact. The aberrant genotypes are eliminated during seed development and thus, are not found in the seedlings or the cultivated varieties. 
(ii) Seedlings

In the reciprocal crosses, the chromosome numbers of the seedlings are strikingly different (text-fig. 2) and show a distinct departure from those of

TABLE 7

Correlation of extra $\mathrm{L}+\mathrm{L}^{n}$ chromosomes on $\mathrm{M}$ and $\mathrm{S}$ in the embryonic progenies of diploid-triploid reciprocal crosses

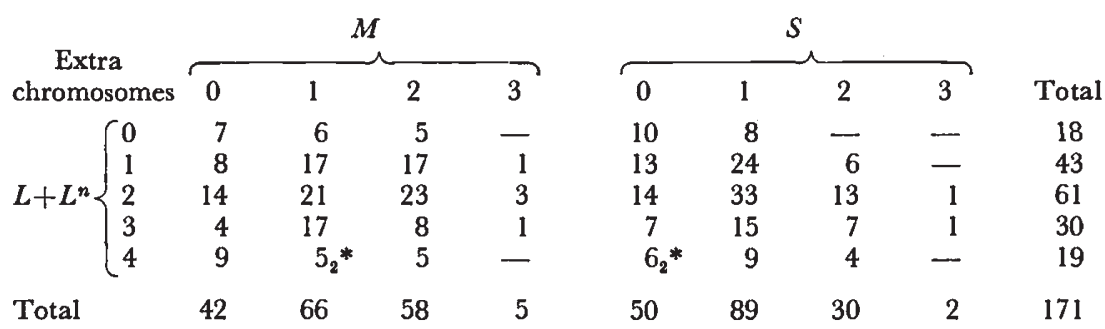

* One each with five and six chromosomes.

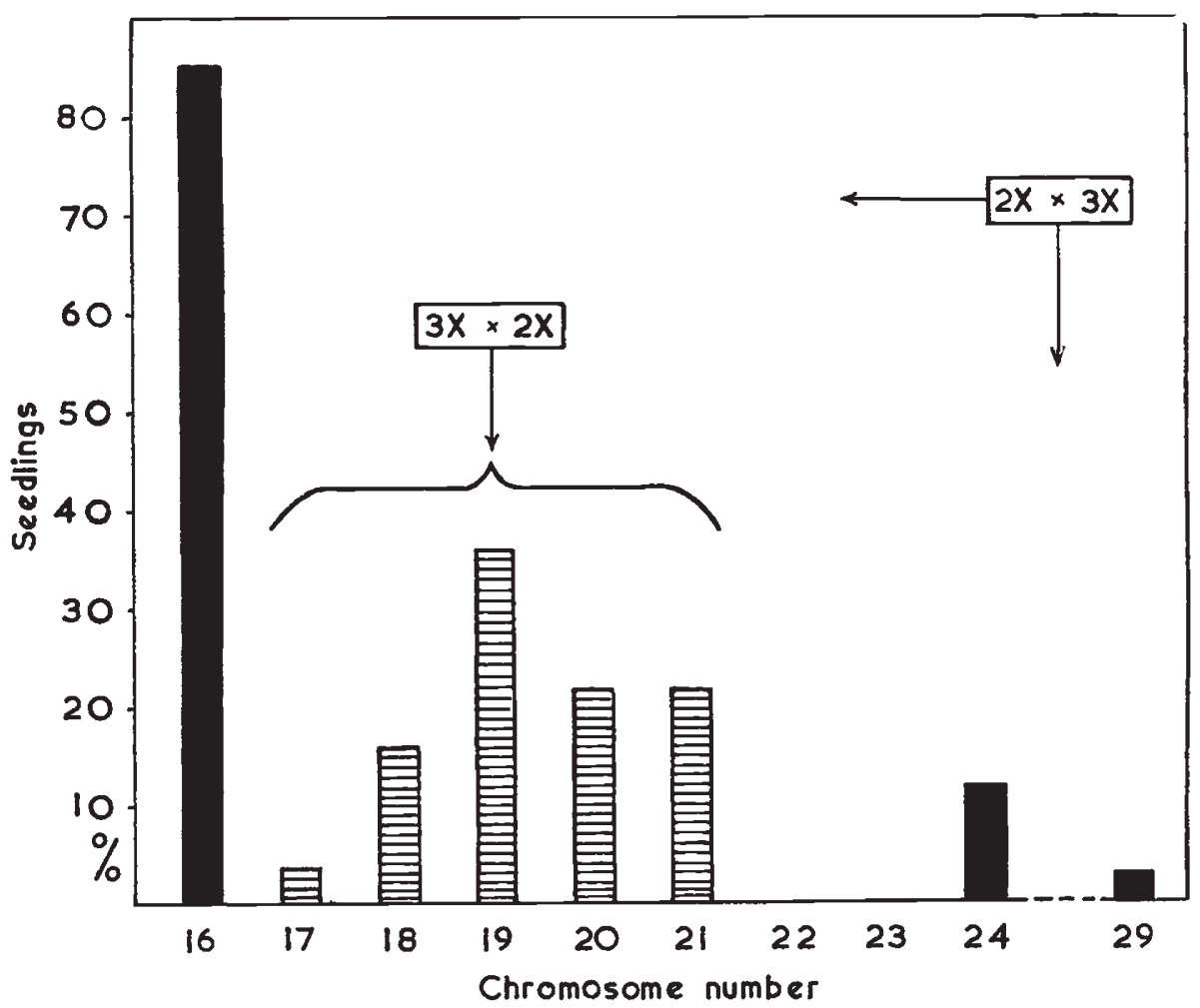

FIG. 2.-Chromosome distribution in the seedlings of diploid-triploid crosses. One seedling with 29 chromosomes is unexpectedly produced by the functioning of an unreduced gamete.

the embryos in the respective crosses ( $c f$. table 6$)$. The elimination pattern in these crosses varies according to the seed parent involved. When this is diploid, selection against the aneuploids is very rigorous as it in other 
genera (see Ved Brat, 1964). In hyacinth it is due not to the non-functioning of unbalanced pollen but to the selective elimination occurring during seed development. However, hyper-triploid aneuploids survive on a diploid seed parent although their formation is very rare. Selective elimination of the aneuploids during seed development and germination explains Upcott and Philp's Fertility Rule (i.e., the fertility of a diploid-triploid cross is inversely proportional to the basic number of chromosomes of the species). Primula sinensis

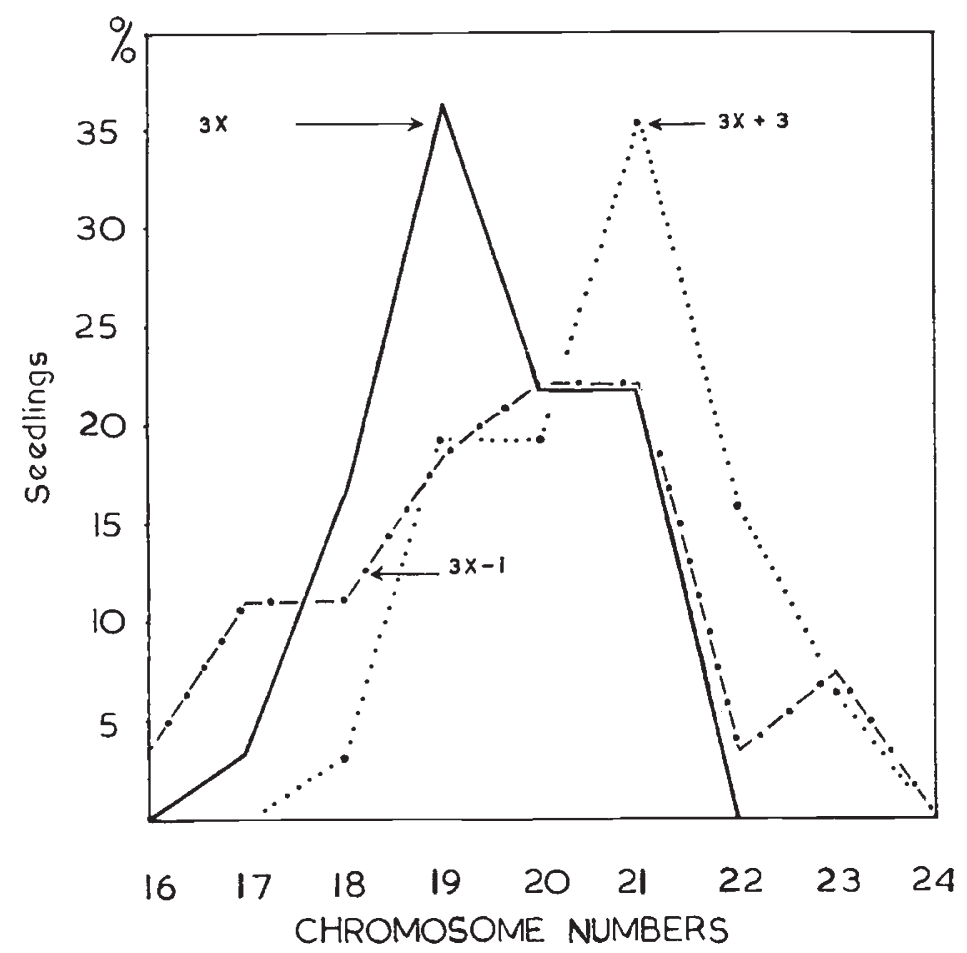

Frg. 3.-Chromosome distribution in the seedling progenies of hyacinth crosses made with the pollen of the diploid on $3 x, 3 x-1$, and $3 x+3$. Only the female parent is named in the figure.

(a) Showing full chromosome complement.

$(x=8)$ and Campanula persicifolia $(x=8)$ are exceptional in producing no seed (Darlington, 1931; Gairdner and Darlington, 1931). However, in all these cases the triploids behave differentially as pollen and seed parents, and this is why they have been often used as seed parents for producing trisomics.

(b) Progenies of hypo- and hyper-triploids

Delight $(3 x-1 S)$ and L'Innocence $(3 x+3 L)$ were crossed with the diploids P. Irene and P. Pearl respectively. During elimination, numerical discrimination of chromosomes is more rigorous in the latter than the former (text-fig. 3). But, in both the progenies, $L+L^{n}$ chromosomes show skewed distributions although their means remain near the expectation $(10.07$ and 11.13 as compared to 10.00 and 11.50 respectively). 


\section{(c) Progenies of tetraploid $\times$ triploid}

The tetraploid gives better fertility than the diploid when both are pollinated with the triploid. Consequently, the seedling progenies show far less numerical discrimination of chromosomes (table 8). The selection

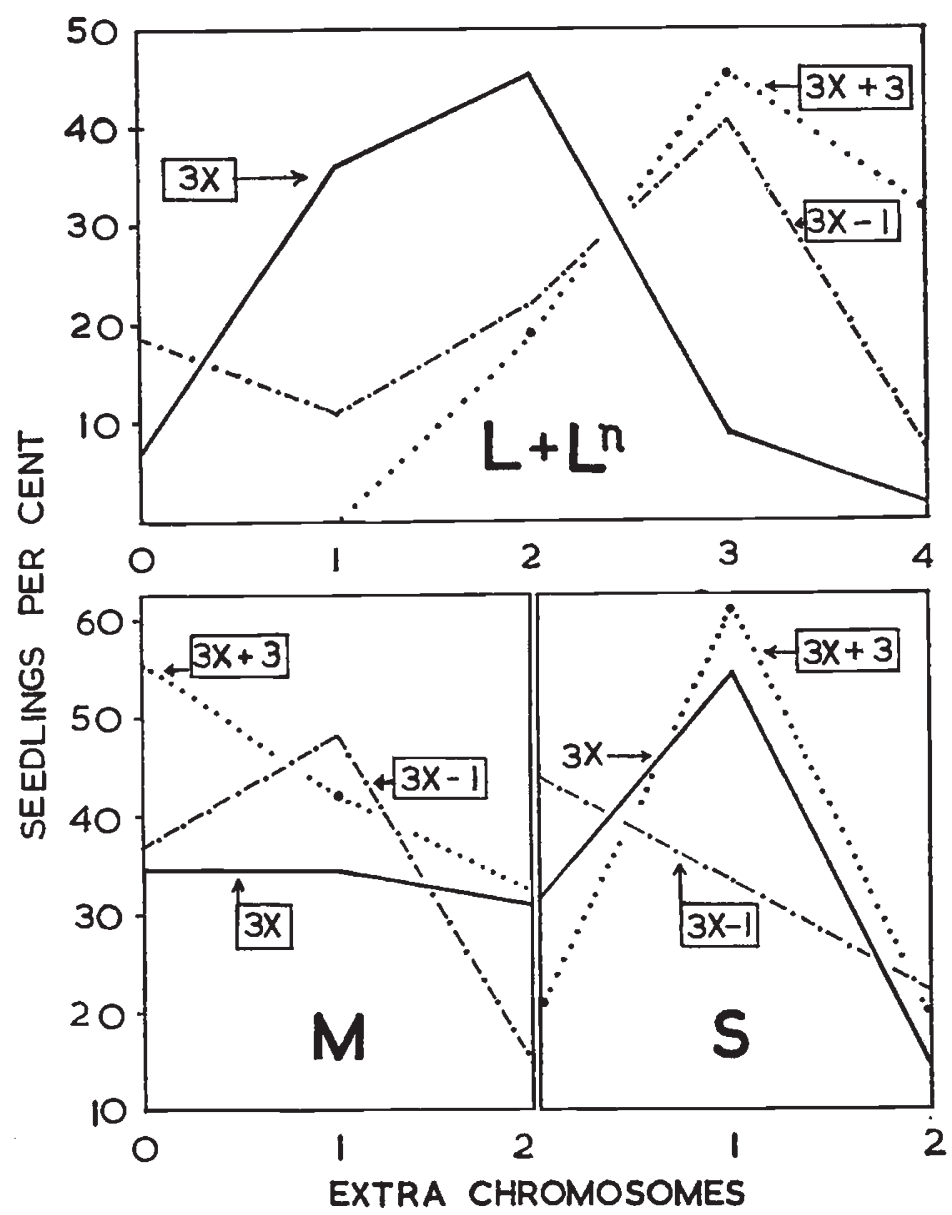

Fig. 3

(b) Showing the three types of chromosomes separately.

pattern displayed thus suggests that the zygotes with more than the triploid chromosome number provide a new balance which can withstand the selection pressure during seed development. Probably that is why a zygote with 29 chromosomes can survive in $2 x \times 3 x$ cross (see text-fig. 2). But, this may not hold good for all possible combinations of chromosomes.

The chromosomal constitution of tetraploid-triploid progenies of hyacinth is similar to those of maize but not of Oenothera and Anthoxanthum (see Borril and Carrol, 1965). However, in all these genera the elimination pattern is similar in diploid-triploid crosses, and it is the seed parent which is important for determining the elimination pattern. Survival of a hypo-triploid seedling $\left(2 n=23=8 L+3 L^{n}+4 M+8 S\right.$, plate I, fig. 3), however, in tetraploid- 
triploid cross is usual and analogous to 29 chromosome seedlings in maize (Punnyasingh, 1947). It could arise from the fusion of haploid pollen with a 15-chromosome egg.

\section{Selection of Garden Varieties}

(a) Seedlings and bud sports

The hyacinth aneuploids are unique in producing seeds and thus most of the varieties have been raised from seedlings. In this respect they differ from Tulipa, where the progenies of the triploids have poor viability and the surviving offspring are completely sterile (Upcott and Philp, 1939). Thus, in hyacinth, the surviving offspring display the most unusual balance with the result that the varieties in cultivation show practically all chromosome numbers from diploid to tetraploid.

TABLE 8

Chromosome distribution in the seedling progenies of tetraploid-triploid crosses

$\begin{array}{ccccccccccccc}\text { Type } & \overbrace{23} & 24 & 25 & 26 & 27 & 28 & 29 & 30 & 31 & 32 & \text { Total } & \text { Mean } \\ L+L^{n}+M+S & 1 & 1 & 1 & 4 & 6 & 3 & 8 & 5 & 7 & 3 & 39 & 28.64\end{array}$

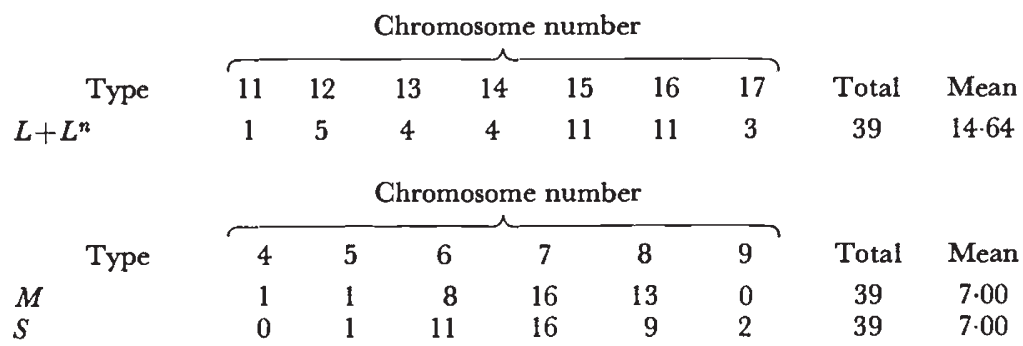

Some varieties, however, have arisen as bud variations which show a change in chromosome number and/or morphology (Darlington et al., 1951). Thus, Queen of Whites has an $S_{2}$ chromosome instead of the $S_{1}$ which is found in the parental form, the Queen of Blues.

A very remarkable case is the origin of Marconi from Cardinal Wiseman. It involves a drop of three chromosomes. Darlington et al., however, doubt the validity of the chromosome count of the parental form which has indeed, an unusual complement $(12 L+8 M+7 S=27)$. But the origin of such genotypes is not impossible as equally unbalanced seedlings have been recorded from the progeny of $4 x \times 3 x$ cross (plate I, figs. 4-6) during the present experiments.

Madame du Barry is a synonym for Van Tubergen's Scarlet which produces very deep scarlet flowers. Its mutant form Scarlet Perfection has double flowers, but the chromosomes in both the forms are similar in number and morphology (plate II, fig. 1).

During the present studies I have found salmon-coloured flowers on a fasciated inflorescence of bright-pink-flowered Anne Marie. Some bulbs also produced two spikes each, one with the parental colour and the other 
with the mutant one. The variation probably arose as a chimera but it was not accompanied by any change in the morphology and/or number of chromosomes.

\section{(b) Balance in the unbalanced seedlings}

The unbalanced varieties have been selected for fashion, beauty and vigour, evidently in competition with the balanced forms. Presumably,

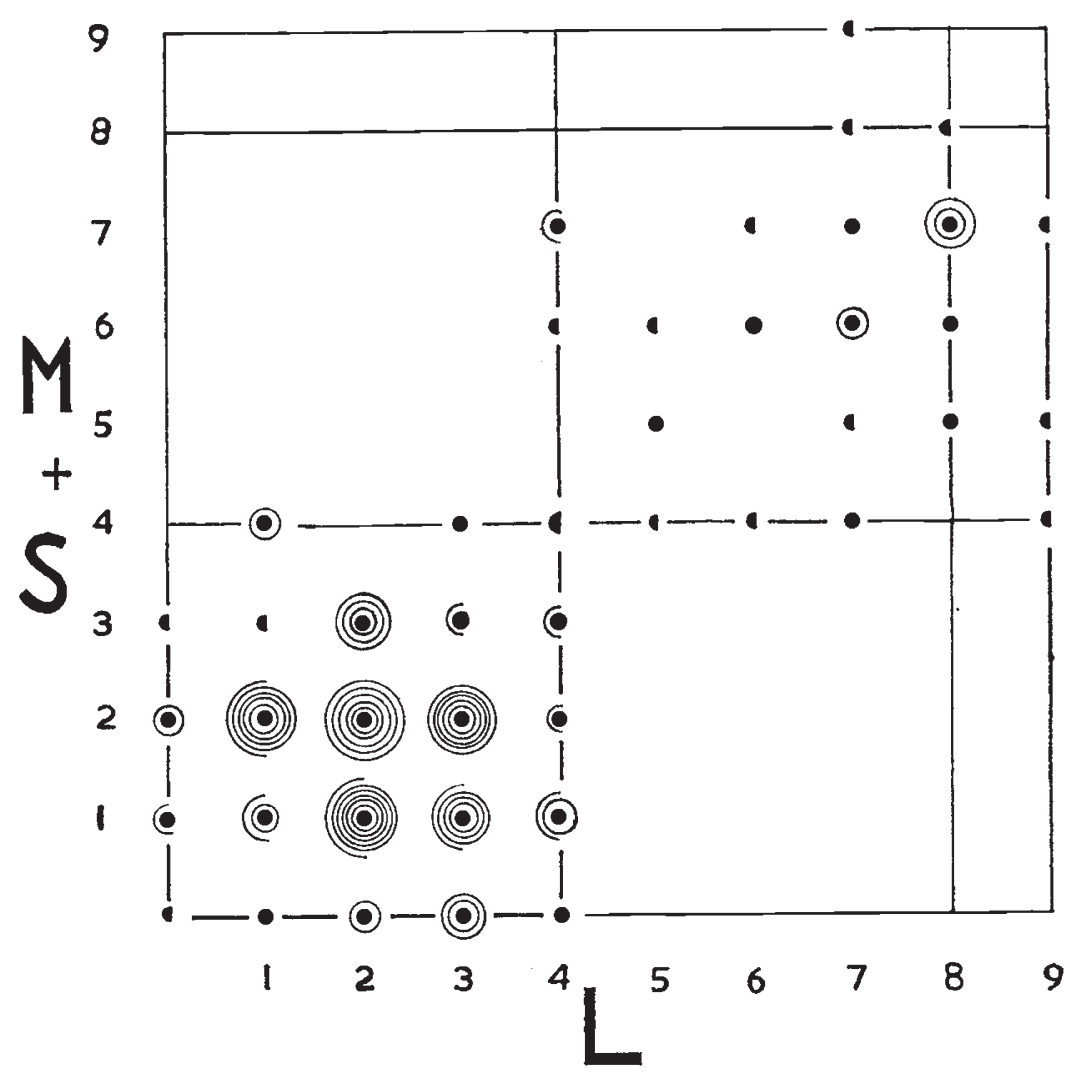

FIG. 4.-Correlation of extra $L$ chromosomes on $M+S$ in the complement's 152 seedlings, all aneuploids except one triploid obtained from different crosses. Selected combinations are confined to the limit of $8: 8$, as also found in the garden varieties. Each circle represents two seedlings and half-circle as one.

some of the unbalanced seedlings are unable to maintain proper growth and development during later years so as to form good bulbs. Thus the garden varieties form a non-random sample of the population which could comprise the seedlings from all possible crosses (text-figs. 4 and 5). Selected combinations of chromosomes in the varieties are based on preferences for an even number of $M$ and odd number of $S$ chromosomes (Darlington and Mather, 1944; Darlington et al., 1951). Such preferences are not found in the seedlings (table 9), suggesting a definite selection pattern in the varieties. The seedlings and the varieties are, however, similar in having the mean number of $L$ chromosomes greater than that of $M+S$ 
together; this must be due to the selection rather than to chromosome loss during meiosis.

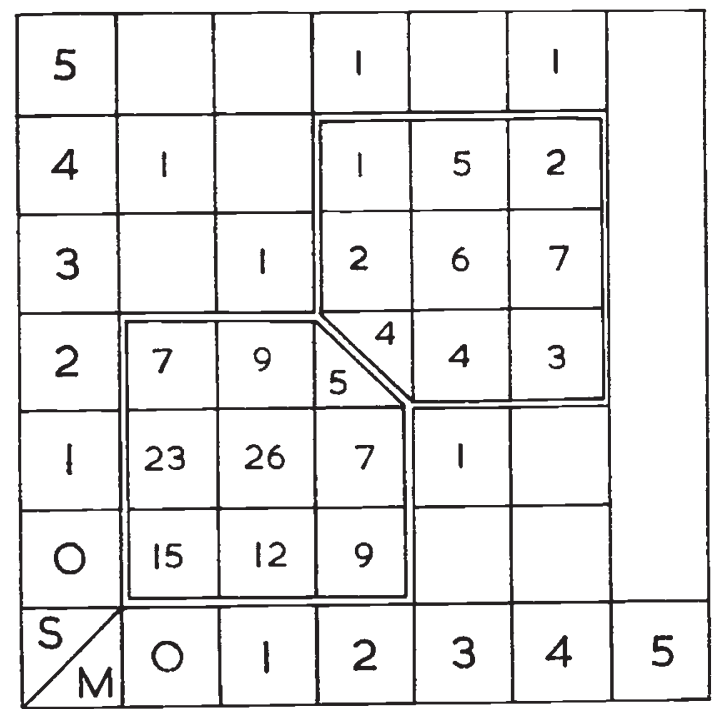

FIG. 5.-Correlation of $M$ chromosomes on $S$ in the somatic complements of 152 seedlings, the same as in text-fig. 4. The limits of the selected combinations are shown by the double lines.

TABLE 9

Distribution of extra L, M and S chromosomes in 152 unbalanced seedlings from different crosses showing preferences for odd and even numbers of chromosomes during selection

Chromosome number

\begin{tabular}{|c|c|c|c|c|c|c|c|c|c|}
\hline Type & 4 & 5 & 6 & 7 & 8 & 9 & Odd & Even & Mean \\
\hline$M$ & 46 & 48 & 29 & 16 & 13 & 0 & 64 & 88 & 1.36 \\
\hline
\end{tabular}

Chromosome number

$\begin{array}{lrrrrrrrrrrrrr}\text { Type } & 8 & 9 & 10 & 11 & 12 & 13 & 14 & 15 & 16 & 17 & \text { Odd } & \text { Even } & \text { Mean } \\ M+S & 15 & 35 & 42 & 16 & 12 & 6 & 10 & 13 & 2 & 1 & 71 & 81 & 2.77 \\ L & 9 & 23 & 37 & 32 & 18 & 4 & 4 & 11 & 11 & 3 & 73 & 79 & 3.08\end{array}$

\section{Fertility AND SELective elimination}

(a) Variation amongst crosses

The fertility of a cross depends upon the balance and viability of both the gametes and the zygotes involved. Evidently, their selective elimination is a more complex process than the one simply based on the numerical correlation of chromosomes in the complement. In the present experiments, most of the crosses involve parents one at least of which produces mostly unbalanced gametes. They are $4 x \times 3 x,(3 x-1) \times 2 x, 2 x \times 3 x$, or $3 x \times 2 x$. The only two sets of crosses which involve parents and gametes both with balanced chromosome numbers are $2 x \times 2 x, 2 x \times 4 x$, or $4 x \times 2 x$. 
Poor fertility of diploid-diploid crosses is presumably due to a failure of pollen tube growth or breakdown of endosperm resulting in seed abortion. In diploid-tetraploid crosses, low fertility is very common and the tetraploid is usually more successful than the diploid as seed parent (see Stebbins, 1958). In hyacinth, the diploid-tetraploid reciprocal crosses are equally poor but the tetraploid bears more seeds which are mostly inviable. This suggests that the haploid pollen in hyacinth can grow better on the stigma of its tetraploid than is the case in the reciprocal cross. This is very similar to Datura, where the poor fertility of the diploid seed parent is due to the bursting of pollen tubes in the styles (Sansome, Satina and Blakeslee, 1942). Plump but inviable seeds which show abnormal development of the maternal tissue as found in Lycopersicon pimpinellifolium (Cooper and Brink, 1945), are not produced in hyacinth. Sooner or later during seed development, endosperm failure leads to the death of the embryo. Where the endosperm failure is complete, the young embryo feeds from the nucellus till it dies (plate II, fig. 2).

\section{(b) Endosperm failure}

During the breakdown of the endosperm, three types of mitotic errors occur. They involve sub-chromatids, chromosomes, and the spindle. The sequence leading to the breakdown of the tissue starts with spontaneous sub-chromatid bridges which persist through a breakage fusion cycle (Brock, 1955). This follows spindle failure and consequently formation of high polyploid nuclei culminating in the breakdown of the tissue. The endosperm failure follows numerical discrimination of chromosomes, and Brock has suggested that it is progressive with the increase of chromosome number. Present data, however, do not support this correlation.

In Trillium, Rutishauser (1956a) found that the frequency of chromosome breakage in the endosperm increased with the addition of fragment chromosomes but, paradoxically, it also improved the fertility of the cross. Thus the fertility is not necessarily limited by the frequency of chromosome breakage in the endosperm. In intergeneric crosses between Trillium and Paris (Rutishauser, 1956b; Rutishauser and La Cour, 1956), the Paris chromosomes are only slightly susceptible to chromosome breakage and the seed abortion results from the limited development of the endosperm as in diploid-hexaploid crosses in Sisymbrium irio (Khoshoo and Sharma, 1959).

The widespread seed inviability arising from endosperm failure has been explained on the basis of quantitative relations between the genomic constitutions of the different tissues involved (see Stebbins, 1958). But the origin of haploids, like the diploid nature of the normal endosperm in Oenothera, does not fit any hypothesis (Valentine, 1955). The physiological balance of the endosperm, however, breaks down due to unusual combination of related or unrelated gametes and Luckwill (1958) suggested that, with this, the hormonal supply from the endosperm to the embryo also breaks down. But, the natural growth of the endosperm itself depends upon the hormones obtained from the nucellus rather than from its own activity (Nakajima, 1962). Thus, the embryo survival depends upon the physiological balance of the nucellus as well as endosperm, and the latter being intermediate is more susceptible to imbalance. In Lycopersicon (Cooper and Brink, 1945) and Datura (Blakeslee et al., 1953), this imbalance is shown by the abnormal growth of maternal tissue. 
Abnormal growth of the antipodals has been suggested as the cause of seed failure when Hordeum jubatum is crossed with Secale cereale (Brink and Cooper, 1944), Elymus virginicus with Agropyron repens (Beaudry, 1951), and wheat with rye (Moss, unpublished). In Hyacinthus, also, giant chromosomes are found in the antipodals (plate II, fig. 5). But they seem to have no correlation with endosperm failure for they appear as a usual feature in the normally reproducing Aconitum (Jachimsky, 1937; Tschermak-Woess, 1956). In Caltha palustris (Grafl, 1941) the antipodals however show endomitosis. Giant chromosomes are also reported in the synergids of Allium nutans (Hakansson, 1957).

\section{SUMmary}

1. Garden hyacinths vary in their chromosome numbers from diploid to tetraploid. Most of the varieties cross with one another but give variable fertility.

2. The polyploids are more fertile as seed parents when crossed with the diploids. In reciprocal crosses, the triploid (Lord Balfour) seed parent is eleven times more fertile than the diploid Pink Pearl. But in $2 x-4 x$ reciprocal crosses the net fertility is more or less similar. The tetraploid produces more seeds which are mostly inviable. In $4 x \times 2 x,(3 x+3) \times 2 x$, and $(3 x+4) \times 2 x$ crosses, the fertility increases progressively.

3. Pollen grains and eggs with different chromosome numbers are equally effective in $2 x-3 x$ reciprocal crosses, but during seed development the aneuploids are completely eliminated when the seed parent is diploid. This is unlike the reciprocal, where only aneuploids survive and the diploids and triploids die.

4. Unexpectedly, some unusual chromosome combinations also survive in the seedlings of $4 x \times 3 x$ cross and selection seems to favour higher chromosome numbers along with some unbalanced genotypes hitherto unrecorded in the garden varieties.

5. Elimination occurs in all crosses presumably due to endosperm failure, but no correlation exists between the chromosome number of the endosperm and its ability to develop properly. Usually, mitotic abnormalities precede endosperm breakdown irrespective of the chromosome numbers and/or the genomic ratios between the tissues involved in seed development.

Acknowledgments.-I am grateful to Professor C. D. Darlington for his advice during the course of this work and to Dr K. R. Lewis for his suggestions during preparation of the manuscript.

\section{REFERENCES}

BEAUDRY, J. R. 1951. Seed development following the mating Elymus virginicus L. $\times$ Agropyron repens. Genetics, 36, 109-136.

BorRiL, M., AND CARrol, C. P. 1965. Fertility and aneuploidy in autopolyploid of Anthoxanthum. Genetica, 36, 420-430.

BRINK, R. A., AND COOPER, D. C. 1944. The antipodal in relation to abnormal endosperm behaviour in Hoereum jubatum $\times$ Secale cereale. Genetics, 29, 391-406.

BROCK, R. D. 1955. Chromosome balance and endosperm failure in hyacinths. Heredity, 9, 199-222.

COOPER, D. C., AND BRINK, R. A. 1944. Collapse of seeds following the mating of Hordeum jubatum and Secale cereale. Genetics, 29, 370-390.

COOPER, D. C., AND BRINK, R. A. 1945. Seed collapse following the mating between diploid and tetraploid races of Lycopersicon pimpinellifolium. Genetics, 30, 376-401.

N 2 
Darlington, c. D. 1931. Meiosis in diploid and triploid Primula sinensis. 7. Genet., 24, 65-96.

DARlington, C. D., AND MATHeR, K. 1944. Chromosome balance and interaction in hyacinths. 7. Genet., 46, 52-61.

DARLINGTON, C. D., HAIR, J. B., AND HURCOMB, R. 1951. The history of garden hyacinths. Heredity, 5, 233-252.

DYER, A. F. 1963. Endosperm development after controlled pollinations within and between species of Trillium and Paris. Chromosoma (Berl.), 14, 549-567.

GAIRDNER, A. E., AND DARLINGTON, G. D. 1931. Ring formation in diploid and polyploid Campanula percisifolia. Genetica, 13, 113-150.

GRAFL, I. 1941. Uber das wachstum der antipodkern von Caltha palustris. Chromosoma (Berl.), 2, 1-11.

Hakansson, A. 1957. Notes on giant chromosomes of Allium nutans. Bot. Not., 110, 196-200.

HAKANSSON, A., AND ELLERSTROM, S. 1950. Seed development after reciprocal crosses between diploid and tetraploid rye. Hereditas (Lund), 26, 256-296.

Jachimsky, н. 1937. Zur zytologie der risen-antipodkerne. Planta. Arch.fur. wiss. Bot., 26, 608-613.

Kнoshoo, T. N., AND Sharma, v. B. 1959. Biosystematics of Sisymbrium irio complex. VI. Reciprocal pollinations and seed failure. Caryologia, 12, 71-97.

LUCKwill, L. c. 1948. The hormone content of the seed in relation to endosperm development and fruit drop in the apple. 7. Hort. Sci., 24, 32-44.

NAKajima, T. 1962. Physiological studies of seed development, especially embryonic growth and endosperm development. Bull. Univ. Usak. Prefecture B, 13, 13-48.

RANDolf, L. F. 1935. Cytogenetics of tetraploid maize. J. Agric. Res., 50, 541-605.

RUTISHAUSER, A. 1956a. Genetics of fragment chromosome in Trillium grandiforum. Heredity, 10, 195-204.

RUTIShaUSER, A. 1956b. Chromosome distribution and spontaneous chromosome breakage in Trillium grandiflorum. Heredity, 10, 367-407.

RUTISHAUSER, A., AND LA COUR, L. F. 1956. Spontaneous chromosome breakage in hybrid endosperm. Chromosoma (Berl.), 8, 317-340.

SANSOME, E. R., SATINA, S., AND BLAKESLEE, A. F. 1942. Disintegration of ovules in tetraploiddiploid and incompatible species crosses in Datura. Bull. Torry Bot. Club, 69, 405-420.

stebbins, G. L. 1958. Inviability, weakness and sterility in interspecific hybrids. Advances in Genetics, 9, 147-215.

THompson, w. P. 1930. Causes of difference in success of reciprocal interspecific crosses. Amer. Nat., 64, 407-421.

тномpson, w. P. 1940. Shrivelled endosperm in species crosses of wheat, its cytological causes and genetical effects. Genetics, 15, 99-113.

TSHERMAK-wOEss, E. 1956. Notizen uber die risenkerne und "Risenchromosomen" in den antipoden von Aconitum. Chromosoma (Berl.), 8, 114-134.

UPCOTT, M., AND PHILP, J. 1939. Genetic structure of Tulipa. IV. Balance, selection and fertility. 7. Genet., 38, 91-123.

valentine, D. H. 1955. Studies in British Primulas. VI. Hybridization between Primula vulgaris Huds. and Primula Veris L. New Phytol., 54, 70-80.

VED BRAT, s. 1964. Experimental studies with the chromosomes of flowering plants (Allium and Hyacinthus). D.Phil. Thesis, Oxford University.

VED BRAT, s. 1967a. Fertility and selection in garden hyacinth. I. Gametic selection. Heredity, 22, 597-601.

veD BRAT, s. 1967b. Genetic systems in Allium. IV. Balance in hybrids. Heredity, 22, 387-396.

WatKins, A. E. 1932. Hybrid sterility and incompatibility. 7. Genet., 25, 125-162.

woodell, s. R. J., And valentine, D. H. 1961. Studies in British Primulas. IX. Seed incompatibility in diploid-autotetraploid crosses. New Phytol., 60, 282-294. 


\section{Plate I}

Fig. 1.-Mitotic complement $\left(2 n=7 L+2 L^{n}+3 M+5 S+1\right.$ Iso. fr.) from a developing embryo carrying a fragment isochromosome. $\times 980$.

Fig. 2.- Mitotic complement $\left(2 n=9 L+2 L^{n}+1 L+4 M+4 S=20\right)$ from a developing embryo carrying a chromosome with a deleted arm. $\times 980$.

Figs. 3-6.-Mitotic complements of unbalanced seedlings from $4 x \times 3 x$ cross. Feulgen staining after $3 \frac{1}{2}$ hours' pretreatment with paradichlorobenzene. $\times 1280$.

Fig. 3. $-8 L+3 L^{n}+4 M+8 S=23$.

FiG. 4. $-8 L+4 L^{n}+8 M+7 S=27$.

Fig. 5. $-13 L+4 L^{n}+5 M+7 S=29$.

Fig. 6. $-11 L+4 L^{n}+6 M+9 S=30$. 


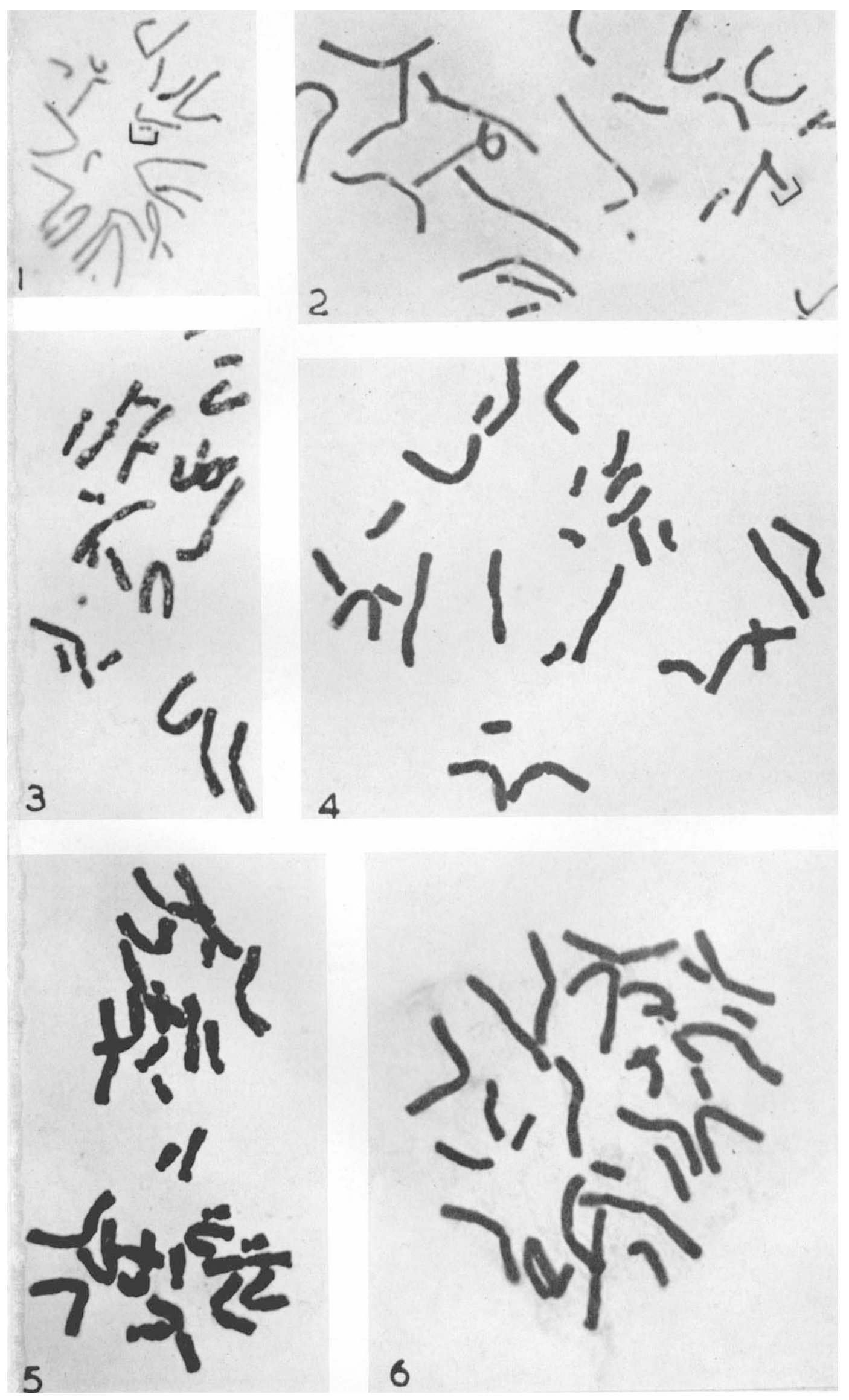


Fig. 1.-Mitotic complement of hyacinth Scarlet Perfection, a mutant form of Madam du Barry. One of the $L$ chromosomes is deficient in both the varieties. $\times 1280$.

FIG. 2.-Whole mount of an embryo sac with young embryo but no endosperm two weeks after pollination in $2 x \times 3 x$ cross. The antipodals have enlarged enormously. $\times 200$.

Frg. 3.-Synchronous mitoses in hybrid endosperm with different grades of polyploid nuclei and persistent bridges connecting two metaphases in a $3 x \times 2 x$ cross. $\times 200$.

Frg. 4.-Spindle failure with the formation of polyploid nuclei and lagging chromatids in hybrid endosperm of a $3 x-1 \times 2 x$ cross. $\times 940$.

Frg. 5.-Giant chromosomes in the antipodals of $2 x$ hyacinth Pink Pearl two weeks after pollination with $3 x$ Lord Balfour. $\times 800$. 

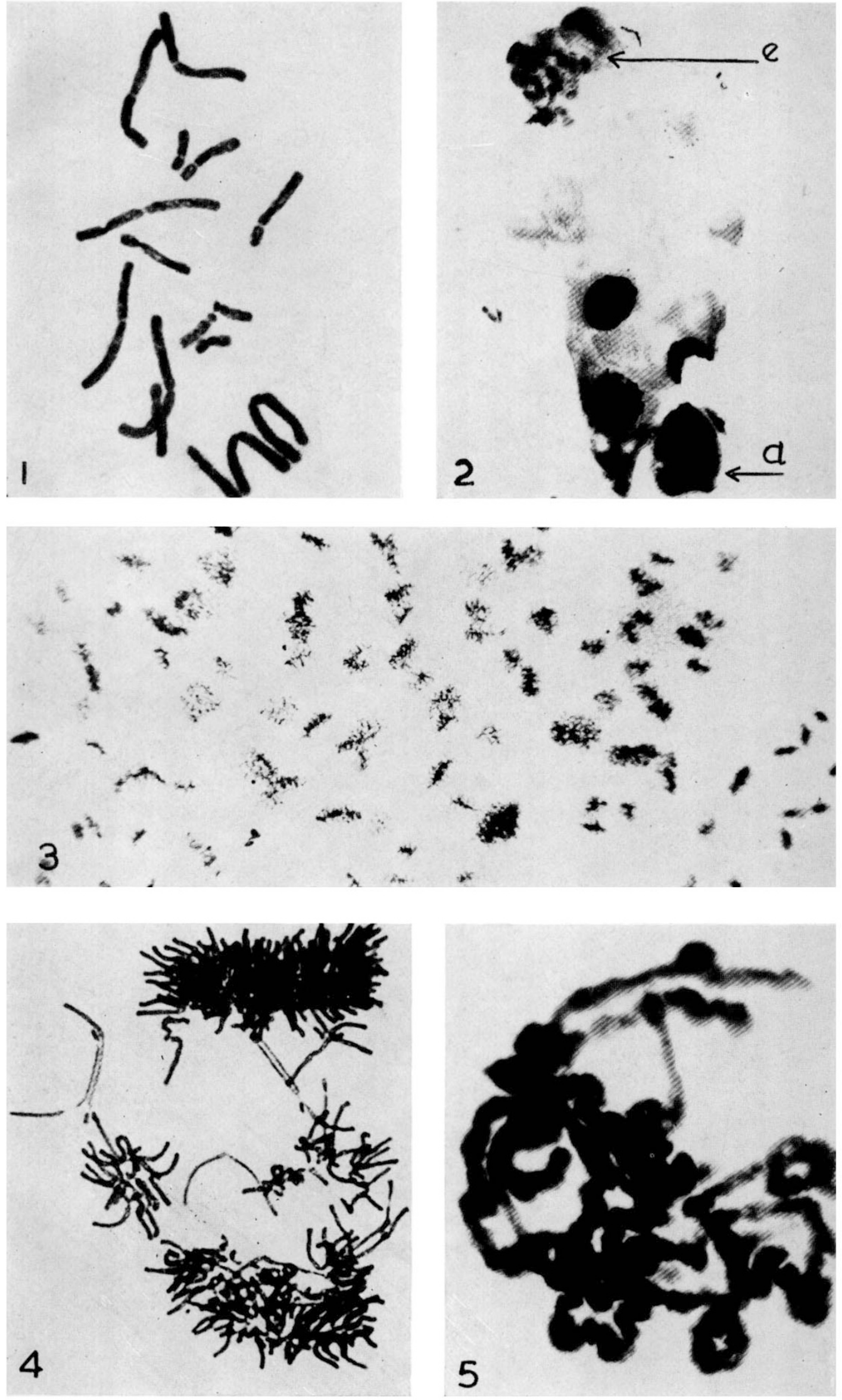